\title{
Article
}

Arq Neuropsiquiatr 2010;68(2):224-227

\section{Psychological assessment in patients with phobic postural vertigo}

\author{
Liliani Souza dos Santos Ferreira' ', Cristiana Borges Pereira², Sueli Rossini³, \\ Aline Mizuta Kozoroski Kanashiro ${ }^{4}$, Carla Cristina Adda ${ }^{5}$, Milberto Scaff ${ }^{6}$
}

\begin{abstract}
Phobic postural vertigo (PPV) is a frequent diagnosis which can be challenging to treat. Objective: To investigate the presence of psychiatric disturbances in patients with PPV; to assess the psychological status of patients using adaptive diagnosis; to verify possible correlations between severity of psychiatric disturbance and adaptive efficacy. Method: A total of nineteen subjects were assessed and two instruments applied: the Primary Care Evaluation of Mental Disorders Questionnaire (PRIME-MD) and the Adaptive Operationalized Diagnostic Scale (AODS), and results from both tests were compared. Results: Fourteen patients presented with mood disorder and thirteen with anxiety. All patients presented compromised adaptive efficacy. Correlation was found between overall outcome on the PRIME and the AODS (tau $=-0.42, p=0.027$ ), Separate analysis revealed correlation between results of the AODS and anxiety disorders (tau $=-0.45, p=0.018$ ) but not with mood disorders (tau $=-0.36, p=0.054$ ). Conclusion: Adaptive compromise was observed in individuals with PPV which was shown to be associated to psychiatric disorders. Key words: dizziness, phobic postural vertigo, mood disorder, anxiety disorder.
\end{abstract}

\section{Avaliação psicológica em pacientes com vertigem postural fóbica}

\section{RESUMO}

A vertigem postural fóbica (VPF) é um diagnóstico freqüente e de tratamento difícil. Objetivo: Investigar a presença de distúrbios psiquiátricos em pacientes com VPF; avaliar as condições psicológicas dos pacientes através do diagnóstico adaptativo. Método: Foram avaliados 19 sujeitos e aplicados dois instrumentos de avaliação: Questionário Primary Care Evaluation of Mental Disorders (PRIME-MD) e Escala Diagnóstica Adaptativa Operacionalizada (EDAO) e comparados os resultados de ambos os testes. Resultados: Quatorze pacientes apresentaram transtorno de humor e treze de ansiedade. Todos os pacientes foram avaliados com adaptação ineficaz. Houve correlação entre o resultado geral do PRIME e da EDAO (tau= -0,42, $p=0,027$ ). Ao se analisar de maneira separada, foi observada correlação entre os resultados da EDAO e os transtornos de ansiedade (tau $=-0,45, p=0,018$ ), não havendo correlação com os transtornos de humor (tau= $-0,36$, $p=0,054)$. Conclusão: Há prejuízo na qualidade adaptativa das pessoas que sofrem de VPF e este prejuízo está associado a transtornos psiquiátricos.

Palavras-chave: tontura, transtorno de humor transtorno de ansiedade, vertigem postural fóbica.

Phobic postural vertigo (PPV) is characterized by a combination of subjective symptoms of oscillatory vertigo, postural instability and balance complaints which manifest as episodes in specific situations ${ }^{1}$.
The diagnosis of PPV is based on the following six characteristic features ${ }^{2}$.To establish the diagnosis, features 1 to 4 were mandatory; features 5 and 6 were optional: (1) Dizziness and subjective disturbance 
of balance during upright posture and gait, despite normal clinical balance tests. (2) Postural vertigo described as fluctuating unsteadiness during a few minutes, or sometimes the perception of illusory body perturbations for a few seconds. (3) Anxiety and distressing vegetative symptoms accompanying and subsequent to the vertigo, although most patients experienced vertigo attacks both with and without excess anxiety. (4) Vertigo attacks that can occur spontaneously, but upon specific questioning are found to be associated with particular constellations of perceptional stimuli (bridges, staircases, empty rooms, streets, driving a car) or social situations (department store, restaurant, concert, meeting, reception) from which the patients have difficulty withdrawing and which they recognize as provoking factors. There is a tendency for rapid conditioning, generalization, and avoidance behavior to develop. (5) Typically, an obsessive-compulsive type personality in patients often found to have affective labiality and mild (reactive) depression. (6) Frequently, onset of the condition following periods of particular stress or after the patient has experienced an illness, usually a vestibular disorder.

Postural imbalance associated to vertigo can lead to insecurity, irritability, loss of self confidence, anguish, anxiety, depression, panic and agoraphobia. Individuals who suffer from vertigo experience concentration difficulties, memory loss and fatigue. Vertigo-associated fantasies are also common such as: feelings of being removed from reality, depersonalization, fear of physical handicap or serious illness ${ }^{3,4}$. PPV is often triggered by a stressing event in the patient's life ${ }^{1}$, such as emotional tension or severe illness and should be treated as a multi-dimensional condition which involves postural, cognitive and emotional factors ${ }^{5}$.

The aims of the present studies were: (1) to investigate the presence of possible psychiatric disturbances in patients with PPV, particularly depression and anxiety; (2) to assess the psychological status of patients using adaptive diagnosis; (3) to verify possible correlations between severity of psychiatric disturbance and adaptive efficacy.

\section{METHOD}

\section{Patients}

A total of 19 subjects of both genders, all diagnosed with PPV and consecutively seen at a Vestibular Disorders Outpatient Unit between 2006 and 2008 were assessed. The study was conducted in accordance with the ethics standards established in the 1964 Helsinki Declaration and was approved by the hospital's Research Ethics Committee. Patients participating in this study signed a written consent statement.

Patients with history of depression and anxiety, cognitive disturbances, psychotic behaviors, mental handicap and alcohol and drugs abuse or dependency were excluded. Patients in use of antidepressants or benzodiazepines to treat other conditions (e.g. migraine, insomnia) and whose medication had been modified within the three months leading up to the initial assessment were also excluded.

\section{Psychological assessment}

Following initial assessment by a neurologist, the patients with PPV were referred for psychological assessment within 10 days of the initial consultation.

Two instruments were used for assessment:

1. The Primary Care Evaluation of Mental Disorders (PRIME-MD) questionnaire was used to obtain the psychiatric diagnosis, previously translated into Portuguese and adapted for use in a Brazilian setting. This questionnaire works to the diagnoses contained in the Diagnostic and Statistical Manual of Mental Disorders - Fourth Edition (DSM-IV), which were modified to facilitate their use in Primary Care services. Some of the subclinical diagnoses were also included given their relevance for clinical management of the patient $t^{6,7}$.

2. The Adaptive Operationalized Diagnostic Scale $(\mathrm{AODS})^{8,9}$ which assesses the adaptive efficacy of the individual according to appropriateness of the set of responses presented to resolve the situation-problem which life presents in four areas: relational affective, which encompasses the set of responses concerning emotions and feelings of the subject in interpersonal relationships and with themselves; productivity, which covers all responses related to work, studies and any other form of occupation; socio cultural, which contains the attitudes and actions of the subject with institutions, values and customs or the culture in which the individual lives; and organic, which denotes physical status and the group of responses on feelings, attitudes and care in relation to the person's own body. The author defined adaptation as the set of responses of a living organism to situations which are constantly changing, enabling them to maintain their organization, however small it may be, consistent with life . $^{8}$

The appropriateness of response is based on three criteria: (1) resolves the problem, (2) provides some kind of reward and (3) does not create inter or intrapsychic conflict.

The use of AODS allows the patients to be classified on a scale according to adaptive efficacy which can be: efficacious or inefficacious adaptation, ranging from mild to critical, as follows: efficacious adaptation: "normal" personality, rare neurotic or characterologic symptoms (character traits, or, low plasticity for making life changes); mild inefficacious adaptation: mild neurotic symptoms, slight characterologic traits, some inhibitions; moderate inefficacious adaptation: some neurotic symptoms, moderate inhibition, some characterologic traces; severe inefficacious adaptation: more limiting neurotic symp- 
toms, restrictive inhibitions, rigidity of characterologic traits; critical inefficacious adaptation: incapacitating neuroses, borderlines, non acute psychotics, extreme characterologic rigidity.

The designation "crisis" exists in each adaptive group and specifies an individual who, when confronted with a problem and is unable to find an answer in the short term, experiences emotional imbalance and tensions. This crisis may occur due to loss (or expectation of loss), or due to gain (or expectation of gain) ${ }^{8,9}$.

\section{Statistical analysis}

In order to allow comparison of the two questionnaires, scores were assigned for results of the PRIME-MD questionnaire according to the severity of the situation and social compromise in the short and medium terms. The scores were assigned as follows: major depressive disorder: 3 , minor depressive disorder: 2 , depressive disorder due to physical disease: 2 ; and dysthymia: 1 ; panic disorder: 3; generalized anxiety disorder: 2 ; and anxiety disorder without other specifications: 1 . The previously established scores on the adapted AODS were as follows: efficacious: 5; mild inefficacious: 4; moderate: 3 to 3,5; severe: 2 to 2,5; and critical: 1,5 . Crisis situations have no affect on scoring.

Kendall's correlation test was used to compare the scales, adopting a significance level of 0.05 .

\section{RESULTS}

\section{Mood and anxiety disorders}

Out of the 19 subjects assessed, 15 were (78.9\%) were females. Ages ranged from 18 to 77 years, with a mean of 53.47 years.
In this sample, 18 individuals (94.7\%) presented at least one diagnosis of psychiatric disorder (Table). Eleven subjects (57.9\%) presented with mixed disturbances, i.e. association of anxiety disturbance with mood disturbance, comprising eight females and three males. Somatoform disorder alone without other specifications was observed in 2 patients (10.5\%).

Mood disorder was found in 14 (73.7\%) patients, where two of these presented with more than one mood disorder. Anxiety disorder was similarly high, being found in 13 (68.4\%) patients where four cases also presented with more than one type of anxiety disturbance.

\section{Adaptive diagnosis}

In terms of adaptive efficacy, all patients presented with inefficacious adaptation, 5 being mild, 5 moderate, 4 severe and 5 critical. Six (31.6\%) patients were in a state of crisis. The patient who did not score on the PRIME presented mild inefficacious adaptation.

\section{Correlation between scales}

Correlation was found between overall outcome on the PRIME and the AODS ( $\operatorname{tau}=-0.42, \mathrm{p}=0.027)$, Separate analysis of mood disorders and anxiety revealed correlation between results of the AODS and anxiety disorders (tau $=-0.45, \mathrm{p}=0.018$ ) but no correlation with mood disorders $(\operatorname{tau}=-0.36, \mathrm{p}=0.054)$.

\section{DISCUSSION}

The sample of 19 patients in this study comprised mainly women at a 4:1 ratio to men. A previous study using the PRIME-MD showed female gender to be a risk factor for psychiatric disturbances. Biological (neuroen-

Table. Description of findings of the 19 patients assessed.

\begin{tabular}{|c|c|c|c|c|c|}
\hline PRIME \AODS & Mild & Moderate & Severe & Critical & Total \\
\hline No disorders & 1 & & & & 1 \\
\hline Somatoform WOS & 1 & 1 & & & 2 \\
\hline Minor depressive disorder & $2(1)^{*}$ & & & & 2 \\
\hline Minor depressive disorder + anxiety disorder WOS & 1 & & & & 1 \\
\hline Minor depressive disorder due to physical disease & & & 1 & & 1 \\
\hline Major depressive disorder + anxiety disorder & & 1 & $2(1)^{*}$ & $1(1)^{*}$ & 4 \\
\hline Major depressive disorder + panic disorder + generalized anxiety disorder & & & & 2 & 2 \\
\hline Major depressive disorder + panic disorder + anxiety disorder WOS & & & & 1 & 1 \\
\hline $\begin{array}{l}\text { Major depressive disorder + minor depressive disorder due to physical disease } \\
+ \text { generalized anxiety disorder + panic disorder + compulsive eating }\end{array}$ & & $1(1)^{*}$ & & & 1 \\
\hline $\begin{array}{l}\text { Major depressive disorder + minor depressive disorder due } \\
\text { to physical disease }+ \text { generalized anxiety disorder }\end{array}$ & & & $1(1)^{*}$ & & 1 \\
\hline Dysthymia + anxiety disorder WOS & & $1(1)^{*}$ & & & 1 \\
\hline Generalized anxiety disorder & & 1 & & & 1 \\
\hline Anxiety disorder WOS & & & & 1 & 1 \\
\hline Total & $5(1)^{*}$ & $5(2)^{*}$ & $4(2)^{*}$ & $5(1)^{*}$ & 19 \\
\hline
\end{tabular}

WOS: without other specifications. ( )*: number of patients experiencing crisis. 
docrinologic) and sociologic (role played in society) aspects explain the majority of psychiatric disorders observed in this group ${ }^{10}$. Women more frequently report vertigo, feelings of impotence and paralysis, faced with the demands of society ${ }^{11}$.

PPV is linked to psychiatric disorders while its symptoms are considered diagnostic criteria for diseases such as depression and anxiety ${ }^{12}$. In some circumstances it is difficult to ascertain whether these disorders are primary or secondary to vestibular dysfunction because some psychological symptoms may be a cause, consequence or coexist with vertigo crises $^{13}$. Several authors have highlighted psychiatric compromise in vestibular disorders ${ }^{14-16}$. Psychosomatic processes may possibly contribute to the development, maintenance or severity of dysfunction of the vestibular system. In other cases dizziness may represent only one somatic manifestation of anxiety whereas in others, dysfunction in the vestibular system may coexis ${ }^{17,18}$.

One of the non-compulsory criteria for PPV diagnosis is mild depression, anxious and compulsive-obsessive personality traits ${ }^{19}$. In the present study, both mood disorder and anxiety were observed in more than half of the patients. The association between these disorders and the presence of further disturbances from the same group in a single individual was also frequent. Moreover, $52.6 \%$ of patients were found to present with major depression, impairing quality of life. Two patients initially had a less severe condition of minor depression due to physical disease but later evolved to major depression. Although the prevalence of depression can be relatively high in neurologic patients, especially in moderate and severe form $\mathrm{s}^{20}$, other studies have not observed increased depression in patients $\mathrm{PPV}^{13}$.

Generalized anxiety disorder was diagnosed in 26.3\% of patients and panic syndrome in $21.1 \%$. In spite of this compromise, some patients did not limit their everyday activities or remain housebound, which indicated the absence of feelings of insecurity and fear.

The presence of psychiatric disturbance in PPV does not invalidate its diagnosis but rather, points to the need for a more thorough assessment using objective instruments to measure the psychiatric disorder, and highlights the importance of a multi-professional team. In our literature review, we found indications for psychiatric and interdisciplinary assessment and for treatment and prophylaxis of these disorders ${ }^{15,16,18,21}$.

No patients in our sample showed vertigo together with efficacious adaptation, i.e. all the PPV patients presented adaptive inefficacy to some degree, presenting compromise in the quality of solutions to problems and the vicissitudes of life. All reported to have experienced traumas or loss (of an organic or extreme nature) prior to the onset of PPV, corroborating the results of earlier studies ${ }^{13}$.

The relationship between inefficacious adaptation and psychiatric disorders found in the patients of this sample, raise the question of somatization, in other words, inefficacious adaptation may be considered a trigger for diseases such as PPV ${ }^{5,22}$. Triggering of somatoform diseases such as PPV may possibly stem from the way a person deals with problems and personal issues in several sphere of life and their degree of adaptation to these issues. The psychological status of the patients was found to be associated with these individuals' current level of satisfaction with their state of resolution of their problems, and in some spheres of life these patients were dissatisfied, in line with the diagnosis of inefficacious adaptation.

Compromise in emotional and adaptive issues of the patient, associated with the mood and anxiety disorders, support the hypothesis of somatization in PPV, and highlight the need for an interdisciplinary team to diagnose and treat PPV.

\section{REFERENCES}

1. Brandt T, Dieterich M. Phobischer Attacken-Schwankschwindel, Ein neues Syndrom? Münsch Med Wschr 1986;128:247-250.

2. Brandt T,Huppert D,Dieterich M. Phobic postural vertigo: a first follow-up. J Neurol 1994:241:191-195.

3. Beidel DC, Horak FB. Behavior therapy for vestibular rehabilitation. J Anxiety Disord 2001;15:121-130.

4. Staab JP. Chronic dizziness: the interface between psychiatry and neuro-otology. Curr Opin Neurol 2006;19:41-48.

5. Holmberg J, Karlberg M, Harlacher U, Rivano-Fischer M, Magnusson M. Treatment of phobic postural vertigo: a controlled study of cognitive-behavioral therapy and self-controlled desensitization. J Neurol 2006;253:500-506.

6. Spitzer RL, Williams JB, Kroenke K, et al. Utility of a new procedure for diagnosing mental disorders in primary care. The PRIME-MD 1000 study. JAMA 1994;272:1749-1757.

7. Linzer M, Spitzer R, Kroenke K, et al., Gender, quality of life and mental disorders in primary care: results from the PRIME-MD 1000 study. Am J Med 1996;101:526-533.

8. Simon R. Psicologia clínica preventiva: novos fundamentos. São Paulo: EPU 1989

9. Simon R. Psicoterapia breve operacionalizada: teoria e técnica. São Paulo: Casa do Psicólogo 2005.

10. Benseñor IM, Pereira AC, Tannuri AC, et al.Hipertensão arterial sistêmica e morbidade psiquiátrica em ambulatório de hospital terciário. Arq Neuropsiquiatr 1998;56:406-411.

11. Holmberg J, Karlberg M, Harlacher U, Magnusson M. Experience of handicap and anxiety in phobic postural vertigo. Acta Otolaryngol 2005;125: 270-275.

12. Brandt T. Phobic postural vertigo. Neurology 1996;46:1515-1519.

13. Staab JP, Ruckenstein MJ. Which comes first? Psychogenic dizziness versus otogenic anxiety. Laringoscope 2003;113:1714-1718.

14. Staab JP. Chronic dizziness: the interface between psychiatry and neuro-otology. Curr Opin Neurol 2006;19: 41-48.

15. Eckhardt-Henn A, Best C, Bense C, et al. Psychiatric comorbidity in different organic vertigo syndromes. J Neurol 2008;255: 420-428.

16. Jacob RG, Whitney SL, Detweiler-Shostak G, Furman JM. Vestibular rehabilitation for patients with agoraphobia and vestibular dysfunction: a pilot study. J Anxiety Disord 2001;15:131-146.

17. Yardley L, Redfern MS. Psychological factors influencing recovery from balance disorders. J Anxiety Disord 2001;15:107-119.

18. Ardic FN, Atesci FC. Is psychogenic dizziness the exact diagnosis? Eur Arch Otorhinolaryngol 2006;263:578-581.

19. Huppert D, Strupp M, Rettinger N, Hecht J, Brandt T. Phobic postural vertigo: a long-term follow-up (5 to 15 years) of 106 patients. J Neurol 2005;252:564-569.

20. Hilgert C, Thormann NJ, Farina JI, Lemos P. Prevalência de sintomas depressivos em pacientes avaliados em ambulatório de neurologia geral e sua relação com indicadores de alcoolismo e qualidade de vida. SNC em Foco 2008;4: 13-23.

21. Best C, Eckhardt-Henn A, Diener G, Bense S, Breuer P, Dieterich M. Interaction of somatoform and vestibular disorders. J Neurol Neurosurg Psychiatry 2006;77:658-664

22. Jacob RG, Furman JM. Psychiatric consequences of vestibular dysfunction. Curr Opin Neurol 2001;14:41-46. 